\title{
The Effect of Eurycoma longifolia Jack on SICAM-1 and eNOS in Rats with High Fat Diet
}

\author{
Anas O. H. Ashkurfu', Kis Djamiatun² \\ ${ }^{I}$ Student in Biomedical Science Master Program Faculty of Medicine Diponegoro University, Semarang, \\ Indonesia \\ ${ }^{2}$ Biomedical Science Master Program Faculty of Medicine Diponegoro University, Semarang, Indonesia
}

\section{Article Info Abstract}

History:

Received: 17 May 2018

Accepted: 26 Jun 2018

Available: 31 July 2018

\begin{abstract}
Background: High fat diets are known to cause a positive fat balance and consequently to the accumulation of adipose mass. The molecular mechanisms underlying the anti-inflammatory activity $\beta$-carboline alkaloids E. longifolia, which may be useful to prevent or treat diseases of inflammation. Recent studies showed that E. longifolia Jack protected HFD animal model from atherosclerosis based on the reducing of atherosclerotic plaque size and formation HFD-rats treated with E. longifolia Jack.
\end{abstract}

Objective: To prove that Eurycoma longifolia has anti inflammatory effect on endothelial cell blood vessels of Sprague Dawley rat with high fat diet.

Method: Study design was experimental study, by used Randomized Post Test only Control Group Design with Kruskal-Wallis test to analyzed the differences among groups and followed by a Mann Whitney test. Treatment is ethanol or water extract of Eurycoma longifolia Jack, and outcome are sICAM-1 and eNOS levels. Thirty Sprague Dawley (SD) Rat, were divided into 6 groups. C(-) was SD group, $\mathrm{C}(+)$ was group with HFD, $\mathrm{X}_{1}$ (SD treated with EL dosage $10 \mathrm{mg} / \mathrm{kg}$ ), $\mathrm{X}_{2}$ (SD treated with EL dosage $15 \mathrm{mg} / \mathrm{kg}$ ), $\mathrm{X}_{3}$ (HFD treated with EL dosage $10 \mathrm{mg} / \mathrm{kg}$ ), $\mathrm{X}_{4}$ (HFD treated with EL dosage $15 \mathrm{mg} / \mathrm{kg}$ ).

Result: No significant difference in sICAM-1 that was found among the studied groups. sICAM-1 levels of X1 and X2 groups were not different than those of negative control group. No different was observed between sICAM-1 level of X3 group than positive control group. There is significant difference in eNOS among six group studied. The control negative group was not significance different than control positive, $\mathrm{X} 2, \mathrm{X} 3$, and $\mathrm{X} 4$. X1 showed significant different with negative control, $\mathrm{X} 3$ and $\mathrm{X} 4$. The positive control showed that no significant different than $\mathrm{X} 1, \mathrm{X} 2, \mathrm{X} 3$, and $\mathrm{X} 4$.

Conclusion: Eurycoma longifolia has anti-inflammatory effect especially on eNOS of Sprague Dawley rat with high fat diet.

Keywords: Eurycoma longifolia Jack; sICAM; eNOS; HFD.

\section{INTRODUCTION}

High fat diets are known to cause a positive fat balance and consequently to the accumulation of adipose mass, this diet does not seem to stimulate fat oxidation in the same way in obese and lean subjects ${ }^{1}$.

\footnotetext{
* Corresponding author:

Anas O. H. Ashkurfu

E-mail: anasshkurfu@gmail.com
}

The HFD increases the level of circulating bad cholesterol which boosts the cardiovascular event risk. HFD also increases the risks of other diseases include diabetes, stroke, and some types of cancers. The oxidative stress occurs due to HFD, this is then results in hypertension and metabolic disorder ${ }^{2,3}$.

HFD also causes obesity which became a worldwide epidemic and a major risk factor of several diseases including metabolic syndrome. ${ }^{4}$ Globally, about $39 \%$ of adults aged 18 years and over were overweight in 
2014 and $13 \%$ of them are clinically obese. ${ }^{5}$ Therefore, prevention and treatment of obesity is an important factor for a healthy condition. The reduction of nutrient digestion and absorption to develop inhibitors of the enzyme without altering the main mechanisms in the digestive system into the most important strategies in the treatment of obesity. 6,7

HFD was an inducing factor for intercellular adhesion molecule-1 (ICAM-1) expression in the aorta of Wistar rats. HFD effect on ICAM-1 seems to be time dependent. ICAM-1 is one of the first events in the formation of atherosclerotic lesions. Additionally, soluble ICAM-1 measurement of the concentration in plasma is a reliable index of the expression of the molecules in the Wistar rat aorta. ${ }^{8}$ Previous studies have found that HFD up-regulated Cav-1 and down regulated of eNOS activity in rat thoracic aorta; switch to a normal diet is restored levels of Cav-1 and eNOS; no change in Cav-1 or eNOS expression was observed in DR rats ate a highfat diet; high-fat diet increased eNOS (Ser1177) and Akt (Ser473) phosphorylation in diet-induced obese mice. ${ }^{9}$

The use of natural products in health problem now become noticeable. ${ }^{10}$ Eurycoma longifolia Jack (Simaroubaceae family) is one of the most popular medicinal plants in Southeast Asia, including Myanmar, Thailand, Laos, Indonesia, Cambodia, and Malaysia. ${ }^{11}$ Local E. longifolia Jack has many local name, for example: Tongkat Ali (in Malaysia), Bidara Bitter (in Indonesia) and Cay babinh (in Thailand) meaning as a tree that can cure hundreds of diseases. ${ }^{12}$ This plant contains quassinoids, squalene derivatives, neolignans biphenyl, tricullane-type triterpene, canthine-6-one and $\beta$-carboline alkaloids. Quassinoid is a bitter substance found in Simaroubaceae family that has a lot of biological activity as anticancer, antimicrobial, anti-inflammatory and many other protective effect. ${ }^{13}$ Recent studies showed that $E$. longifolia Jack protected HFD animal model from atherosclerosis based on the reduce atherosclerotic plaque size and formation HFD-rats treated with $E$. longifolia Jack. ${ }^{14}$ Similar animal model also showed that E. longifolia Jack reduced levels of triglyceride and blood pressure of HFD-rats. ${ }^{15}$ Antioxidant and anti-inflammatory effect of E. longifolia Jack had been proven in in vitro study. ${ }^{16}$ However, it remains unknown whether any anti-inflammatory effect of $E$. longifolia Jack involves in the protection of HFD-rats.

$\beta$-carboline alkaloid 7-MCPA (7-methoxy- $(9 \mathrm{H}-\beta$ carbolin-1-yl) - (E) -1-propenoat acid) isolated from E. longifolia hairy root culture $\mathrm{Nrf} 2$ is activated via a ROS dependent p38 MAPK and 7-MCPA antiinflammatory effects associated with activation of 7MCPA-induced of Nrf2 / HO-1 pathway. This study clarified the molecular mechanisms underlying the anti-inflammatory activity of $\beta$-carboline alkaloids $E$. longifolia, which may be useful to prevent or treat diseases of inflammation. ${ }^{17}$ Eurycomalactone, 14,15 $\beta$ dihydroklaieanone, and 13.21-dehydroeurycomanone identified as potent inhibitors of NF-kB with IC50 values of $<1 \mathrm{pM}$. $^{18}$ For this study, the mice will be treated and given a high-fat diet EL extract from the roots as much as $5 \mathrm{mg}$ and $10 \mathrm{mg} / \mathrm{kg}$ body weight for 14 days to determine the levels of sICAM-1 and eNOS.

This research aimed to prove that Eurycoma longifolia has anti-inflammatory effect on endothelial cell blood vessels of Sprague Dawley rat with high fat diet.

\section{MATERIALS AND METHOD}

This study design was experimental study, by used randomized post test only control group design. Kruskal-Wallis test was used to analyze the differences among groups and followed by a Mann Whitney test. Population of this study was Sprague Dawley (SD) Rat, with inclusion criteria were: male; weight 150-200 gram; 8 - 9 weeks of age; and healthy indicated by active movement and anatomically normal. Thirty Sprague Dawley (SD) Rat, were divided into 6 groups. $\mathrm{C}(-)$ was SD group, $\mathrm{C}(+)$ was group with HFD, $\mathrm{X}_{1}$ (SD treated with EL dosage 10 $\mathrm{mg} / \mathrm{kg}$ ), $\mathrm{X}_{2}$ (SD treated with EL dosage $15 \mathrm{mg} / \mathrm{kg}$ ), $\mathrm{X}_{3}$ (HFD treated with EL dosage $10 \mathrm{mg} / \mathrm{kg}$ ), $\mathrm{X}_{4}$ (HFD treated with EL dosage $15 \mathrm{mg} / \mathrm{kg}$ ).

Treatment was ethanolic or water extract of Eurycoma longifolia Jack, and outcome were sICAM1 and eNOS levels. High fat diet fed composition were additional cholesterol $2 \%$, cholic acid $0.2 \%$, and pig oil 5\%. This the highest fat diet compotition confeed PARS 200 gram, yolk of quail egg, cholesterol 8 gram, cholic acid 0.8 gram, pig oil 40 $\mathrm{ml}$, water $51.2 \mathrm{ml}$. Total of high fat diet was 40 gram/rat. Before treatment, rats have been adapted for 7 days, observed for healthy condition and was weighted, and then randomly were alocated into 6 groups. Body weight was evaluated every week. Each rat was treated in the separate plastic cage. Every day, researcher scaled the rat's feed to know the intake of rat/ day. During treatment, rat was given high fat diet feed and extract Eurycoma longifolia Jack dosage 10 $\mathrm{mg} / \mathrm{kg} \mathrm{BW}$ and $15 \mathrm{mg} / \mathrm{kg} \mathrm{BW}$ until 60days treatments by force feeding (oral).

\section{RESULTS \\ ICAM-1}

The highest level of ICAM-1 in the group SD was found in $\mathrm{X} 2$ group and followed by negative control and X1 group. The highest level of sICAM-1 in the HFD groups was the positive control group followed by $\mathrm{X} 3$ and $\mathrm{X} 4$ groups (Graph 1.). Normality test showed that the distribution level of SICAM-1 in each group was normally distributed including negative control $(p=0.200), \mathrm{X} 2$ group $(p=0.091)$, positive control $(p=0.200)$, and $\mathrm{X} 4$ group $(p=0.144)$ and not normally distributed in the $\mathrm{X} 1$ and $\mathrm{X} 3$ group $(p=$ 0.003 and $p=0.001$ ), respectively. The homogeneity test with Kruskall Wallis test showed that the group was not homogen $(p=0.023)$. The test showed that no significant difference among groups $(p=0.087)$. 


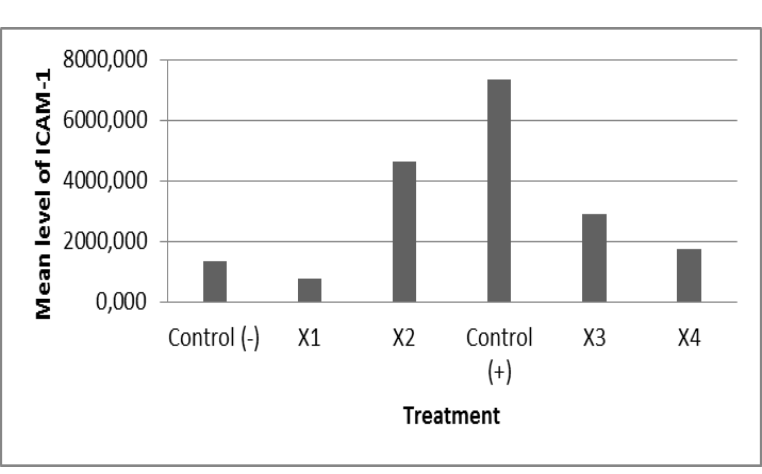

Figure 1. Level of sICAM-1

(Control (-): SD, X1: SD treated with EL dosage 10 $\mathrm{mg} / \mathrm{kg} ; \mathrm{X} 2$ : SD treated with EL dosage $15 \mathrm{mg} / \mathrm{kg}$; Control (+): HFD; X3: HFD treated with EL dosage 10 $\mathrm{mg} / \mathrm{kg}$; X4: HFD treated with EL dosage $15 \mathrm{mg} / \mathrm{kg}$ )

Table 1. Mann Whitney U test Level of sICAM-1

\begin{tabular}{|c|c|c|c|c|c|c|}
\hline \multirow{2}{*}{ Group } & \multirow{2}{*}{$\begin{array}{c}\text { Median } \\
(\mathbf{m i n}- \\
\mathbf{M a x}) \\
\mathbf{p g} / \mathbf{m l}\end{array}$} & $\mathbf{P o s}$ & $\mathbf{X 1}$ & $\mathbf{X 2}$ & $\mathbf{X 3}$ & $\mathbf{X}$ \\
\cline { 5 - 7 } Neg & $\begin{array}{c}(1689.40- \\
15109.48)\end{array}$ & 0.056 & 0.548 & 0.548 & 0.548 & 0.841 \\
\hline Pos & $\begin{array}{c}(-491.36- \\
2863.66)\end{array}$ & & $0.016^{*}$ & 0.310 & 0.095 & 0.056 \\
\hline $\mathbf{X 1}$ & $\begin{array}{c}(11.89- \\
3199.16)\end{array}$ & & & 0.056 & 0.421 & 0.421 \\
\hline $\mathbf{X 2}$ & $\begin{array}{c}(347.39- \\
12928.72)\end{array}$ & & & & 0.151 & 0.310 \\
\hline $\mathbf{X 3}$ & $\begin{array}{c}(-155.86- \\
14606.23)\end{array}$ & & & & & 0.310 \\
\hline $\mathbf{X 4}$ & $\begin{array}{c}(179.64- \\
6050.93)\end{array}$ & & & & & \\
\hline
\end{tabular}

sICAM-1 levels of X1 and X2 groups were not different than those of negative control group ( $p=$ 0.548 and $p=0.548$ ). By comparing of positive and negative control, it was found sICAM-1 level of positive control was nearly significantly lower than negative control control $(p=0.056)$. There was no different result observed between sICAM-1 level of X3 group than positive control group $(p=0.095)$, however sICAM-1 levels of X4 group was nearly significantly lower than positive control $(p=0.056)$. Additionally sICAM-1 levels of both X3 and X4 groups were comparable to that of negative control ( $p$ $=0.548$ and $p=0.841)($ Table 1$)$.

\section{eNOS}

Circulating eNOS level of X1 and X2 was higher than negative control group. Interestingly, eNOS level on positive control group was higherthan negative control group. Those e NOS level on X3 and X4 were below detectable level i.e. lower than either positive or control (Graph 2.)

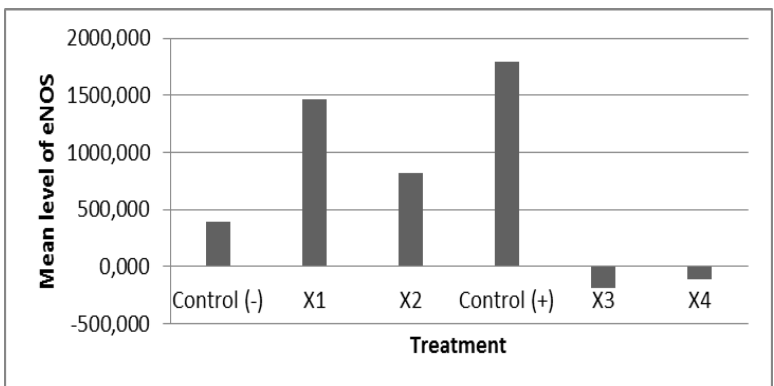

Figure 2. Mean level of eNOS

(Control (-): SD, X1: SD treated with EL dosage 10 $\mathrm{mg} / \mathrm{kg}$; X2: SD treated with EL dosage $15 \mathrm{mg} / \mathrm{kg}$; Control (+): HFD; X3: HFD treated with EL dosage 10 $\mathrm{mg} / \mathrm{kg}$; X4: HFD treated with EL dosage $15 \mathrm{mg} / \mathrm{kg}$ )

Normality test performed in every group studied showed that eNOS level was normally distributed ( $p>$ $0.05)$. These were SD groups negative control ( $p=$ $0.053), \mathrm{X} 1(p=0.200)$ were normally distributed, however X2 group was not normally distributed ( $p=$ $0.010)$. These were also observed in groups with HFD including positive control $(p=0.193), \mathrm{X} 3$ group treated with $10 \mathrm{mg} / \mathrm{kg} \mathrm{BW} /$ day $\operatorname{EL}(p=0.200)$ and X4 group treated with $15 \mathrm{mg} / \mathrm{kg} \mathrm{BW} /$ day EL $(p=0.200)$ normally distributed. Test homogeneity showed that the groups are not homogen $(p=0.000)$. Kruskall Wallis test showed significant difference among six group studied $(\mathrm{p}=0.033)$. The Mann Whitney $\mathrm{U}$ test indicate the different between groups in these study (Table 2).

The control negative group was not significance different than control positive, group II, group III, and group IV ( $p=0.841 ; p=0.310 ; p=0.056 ; p=0.095$ ), respectively. The group I showed significant different with negative control, group III and group IV ( $p=$ $0.032 ; p=0.008$; and $p=0.008)$, respectively. The positive control showed that no significant different than group I, group II, group III, and group IV ( $p=$ $0.690 ; p=0.310 ; p=0.095$; and $p=0.151$ ), respectively.

Table 2. Post Hoc Analyses of eNOS

\begin{tabular}{|c|c|c|c|c|c|c|}
\hline \multirow{2}{*}{ Groups } & \multirow{2}{*}{$\begin{array}{c}\text { Median } \\
(\text { Min }- \\
\text { Max) } \\
\text { pg/ml }\end{array}$} & Pos & $\mathbf{X 1}$ & $\mathbf{X 2}$ & $\mathbf{X 3}$ & $\mathbf{X 4}$ \\
\cline { 5 - 7 } Neg & $\begin{array}{c}(-30.84- \\
4732.55)\end{array}$ & 0.841 & $0.032^{*}$ & 0.310 & 0.056 & 0.095 \\
\hline Pos & $\begin{array}{c}(-30.84- \\
649.65)\end{array}$ & & 0.690 & 0.310 & 0.095 & 0.151 \\
\hline $\mathbf{X 1}$ & $\begin{array}{c}(552.44- \\
2205.04)\end{array}$ & & & 0.151 & $0.008^{*}$ & $0.008^{*}$ \\
\hline $\mathbf{X 2}$ & $\begin{array}{c}(-614.11- \\
48892.76)\end{array}$ & & & & 0.690 & 0.690 \\
\hline $\mathbf{X 3}$ & $\begin{array}{c}(-614.11- \\
260.80)\end{array}$ & & & & & 0.841 \\
\hline $\mathbf{X 4}$ & $\begin{array}{c}(-516.90- \\
552.44)\end{array}$ & & & & & \\
\hline
\end{tabular}

\section{DISCUSSION}

The aim of study was observing the effect of root extract of Eurycoma longifolia in reduces sICAM-1 and eNOS levels of Sprague Dawley rat with high fat diet. This study was done to further explore of the 
mechanism used by EL in protecting vascular endothelial cells in HFD individual. EL effect on sICAM and eNOS levels were observed in rats receiving a combination of EL and HFD for two months period. Endothelial NOS that is commonly expressed in endothelial cells, has many favorable effects, including maintaining vascular dilatation, influencing blood pressure, vasoprotectitive and antiatherosclerosis development and progression. ${ }^{19}$

This study showed that the EL can not reduce levels of ICAM-1 of Sprague Dawley rat that have been fed by HFD. The serum ICAM-1 levels of negative controls receiving normal diet were not different than the positive controls receiving HFD. The HFD may not be sufficient or may not have been feed for a sufficient duration to induce changes in ICAM-1 concentration. The previous study which used baboon as the model of animal showed that high cholesterol of high fat on ICAM-1 did not significant change during 7 weeks period. ${ }^{20}$

This study showed that the eNOS levels of negative control consuming SD only were lower than those of receiving HFD. The eNOS concentrations were significantly lower by consuming HFD for 7 weeks period. ${ }^{20}$ These findings were supported by studies conducted on mice receiving high-fat diets that showed decreased eNOS expression in the liver, heart and medulla kidney. ${ }^{21}$ The HFD mice used in this study were confirmed as animal models of atherosclerosis exhibited by the presence of foam cells in the aortic wall. ${ }^{22}$ The reduced circulating eNOS levels observed in HFD mice may involve the formation of foam cells because the presence of eNOS is capable of preventing the formation of decay cells. $^{23}$ The formation of foam cells, occurs after macrophages take OxLDL. ${ }^{24}$ OxLDL has the ability to inhibit eNOS activity. ${ }^{25}$ Several other factors may explain the decrease in eNOS production in HFD mice. TNF- $\alpha$ may be one of the contributing factors in eNOS level decline. Studies using similar HFD mice showed an increase in the number of cells expressing TNF- $\alpha$ significantly. ${ }^{26}$ TNF- $\alpha$ reduces the rate of eNOS mRNA from endothelial cells of human coronary arteries. ${ }^{27}$ The HFD rat model for atherosclerosis shows reduced production of eNOS.

The regulation of eNOS expression induced by mechanical forces, other stimuli has been shown to modulate the expression of eNOS mRNA in vitro. Most of these stimuli have been implicated in vascular pathophysiology, and they include other mechanical forces, cell growth, cytokines, lipoproteins, growth factors, and oxidative stress. Changes in eNOS mRNA expression and cell ability to produce NO are generally in the order of two to threefold. Although this modulation level may seem simple, it should be remembered that small changes in NO levels may have significant physiological effects. In the case of vascular relaxation, the dose response to NO is quite steep; small increases in NO concentrations resulted in major changes in vascular tone. ${ }^{28}$ Recent research has provided a more detailed understanding of the molecular mechanisms involved in eNOS expression modulation.
Although EL treatment has no significant different on ICAM-1, but EL with a dose of $15 \mathrm{mg} / \mathrm{kg}$ is lower than EL at a dose of $10 \mathrm{mg} / \mathrm{kg}$. Many bioactive compounds have been isolated from E. longifolia, such as quassinoid, canthine-6-one alkaloids, $\beta$ carbolin alkaloids, squalene derivatives, triterpenestirucallane, biphenylneolignans, phenolic compounds, and bioactive steroids. Through a bioguided isolation approach, it has recently identified several inhibitors of the $\mathrm{NF}-\kappa \mathrm{B}$ transcription factor (the kappa-light core factor of activated B cells) at the root of E. longifolia. ${ }^{29}$ One of the most interesting compounds appears to be Eurycoma lactonequassinoid C-19. The transcription factor NF$\kappa \mathrm{B}$ is a central performer in the inflammatory response that regulates, for example, the expression of endothelial adhesion molecules, such as VCAM-1, ICAM-1, or E-selectin, which is essential in inflammatory initiation since adhesion molecules promote extravasation of leucocytes to the site of injury. ${ }^{30} \mathrm{NF}-\kappa \mathrm{B}$ signaling pathways are activated in response to pro-inflammatory cytokines such as TNF $\alpha$ or other pro-inflammatory stimuli, such as lipopolysaccharide (LPS). ${ }^{31}$ NF The family of transcription factors consists of five transcription factor proteins (p65 (RelA), c -Rel, RelB, p50, and p52) which are usually found as homo or heterodimer. In most cell types, the prevalent retained p65 / p50 heterodimer is inactivated in the cytoplasm by closing the sequence of nuclear localization by one of several $\mathrm{kB}$ protein inhibitors $(\mathrm{I} \kappa \mathrm{B})$, which $\mathrm{I} \kappa \mathrm{B} \alpha$ is a prototypical member. ${ }^{31}$ Pro-inflammatory stimulation induces a signal cascade which causes the phosphorylation of IאB kinase (IKK) in the activation loop (Ser177 and Ser181). The phosphorylated IKK complex in turn phosphorylates I $\mathrm{I} B$ to mark degradation through the $26 \mathrm{~S}$ proteasome.

The results of this study also show that EL does not affect the eNOS level. However, the level of eNOS in group IV is higher than in group III. The $E$. longifolia water extract increases the expression of NOS to form NO and also inhibits PDE3, PDE4 and PDE5. It is known to be involved in a myriad of biochemical processes in the human body including smooth muscle relaxation. ${ }^{32}$ Thippeswamy \& Marris reported that NO produced by nNOS induced cGMP synthesis. Penile eruption is a proven androgendependent NO-mediated process. In penile erection, NO places its target molecule from guanylylcyclase that dissolves on the smooth muscle surface of the corpus cavernosum and causes a conformational change in the enzyme leading to increased production of a 3'-5'-cylic messenger guanosine. monophosphate (cGMP) of guanosine triphosphate (GTP). cGMP induces relaxation of smooth muscle in the corpus cavernosum and allows blood to flow into the penis where it becomes trapped. The degradation and loss of cGMP from smooth muscle tissue causes contraction and normal blood flow in and out of the corpora cavernosa. PDE5 is dominant in the penis, breaking cGMP into GMP by catalyzing the reaction that damages the phosphodiester bond ${ }^{33}$. E. longifolia helps maintain high levels of cGMP in the corpora 
cavernosa by pressing PDE5 to break down cGMP. Inhibition of PDE5 increases the duration of cGMP remain in smooth muscle tissue thus increasing. ${ }^{33}$

\section{CONCLUSION}

No significant difference on level of ICAM-1 was found among groups with or without HFD treatment. Significant difference on the level of eNOS was found among groups with or without HFD treatment.

\section{REFERENCES}

1. D.F. Coelho, L.O. Pereira-Lancha, D.S. Chaves, D. Diwan, R. Ferraz, P.L. Campos-Ferraz, J. R. Poortmans and A.H. Lancha Junior. Effect of high-fat diets on body composition, lipid metabolism and insulin sensitivity, and the role of exercise on these parameters. Braz J. Med Biol Res. 2011; 44(10): 966-72.

2. Matsuzawa-Nagata $\mathrm{N}$, Takamura $\mathrm{T}$, Ando $\mathrm{H}$, Nakamura S, Kurita S, Misu H, Ota T, et. al. Increased oxidative stress precedes the onset of high-fat diet-induced insulin resistance and obesity.Metabolism. 2008; 57(8):1071-7.

3. Mai A, Jian-Mei Li. NADPH oxidase activation and oxidative stress in high-fat diet-induced hypertension and metabolic disorders. Heart 2014; 100: A1.

4. A. Barnes. Overweight versus obese: different risk and different management. Tex Heart Inst J. 2015; 42 (3): 237-238.

5. World Health Organization. Global Health Observatory (GHO) data. Overweight and obesity World Health Organization, Geneva 2014.

6. J.W. Yun. Possible anti-obesity therapeutics from nature-a review. Phytochemistry 2010; 71: 1625 1641

7. K.A. Martin, M.V. Mani, A. Mani. New targets to treat obesity and the metabolic syndrome. Eur J Pharmacol. 2015 http://dx.doi.org/10.1016/j.ejphar.2015.03.093.

8. LamprosFotis, GeorgiosAgrogiannis, Ioannis S. Vlachos, AlkistisPantopoulou, AngelikiMargoni, Maria Kostaki, et. al. Intercellular adhesion molecule (ICAM)-1 and vascular cell adhesion molecule (VCAM)-1 at the early stages of atherosclerosis in a rat model. In Vivo. 2012. 26: 243-250.

9. NianhongYang, ChenjiangYing, MingjiaXu, XuezhiZuo, XiaoleiYe, LiegangLiu, et. al. Highfat diet up-regulates caveolin-1 expression in aorta of diet-induced obese but not in dietresistant rats. Cardiovascular Research 2007; 76: 167-174.

10. Daniel A. Dias, Sylvia Urban, and Ute Roessner. A Historical overview of natural products in drug discovery. Metabolites 2012; 2: 303-336.

11. Kuo PC, Damu AG, Lee KK and Wu TS. Cytotoxic and antimalarial constituent from the roots of Eurycoma longifolia. J Bioorg Med Chem. 2004; 12: 537 -544.

12. Guo Z, Vangapandu S, Sindelar RW, Walker LA and Sindelar RD. Biologically active quassinoid and their chemistry: potensial leads for drug design. Curr Med Chem. 2005; 12:190-193.

13. Kuo PC, Shi LS, Damu AG, Su CR, Huang CH, $\mathrm{Ke} \mathrm{CH}, \mathrm{Wu} \mathrm{JB}$, et. al. Cytotoxic and antimalarial beta-carboline alkaloids from the roots of eurycomalongifolia. J Nat Prod. 2003; 66(10): 1324-1327.

14. Fakhria Al-Joufi, Imad M. Al-Ani, Anil K. Saxena, Norlelawati A. Talib, Rafidah $\mathrm{H}$. Mokhtar, Norsidah Ku-Zaifah. Assessment of anti-atherosclerotic effect of Eurycoma longifolia extract on high fat diet model in rats. I: Histological study. Eur. J. Anat. 2016; 20(2): 131-136.

15. Fakhria Al-Joufi, Anil K. Saxena, Imad M. AlAni, Norlelawati A. Talib, Rafidah H. Mokhtar, Norsidah Ku-Zaifah. Anti-atherosclerotic effects of eurycomalongifolia in rats fed on high fat diet. IMJM. 2015: 14.

16. C.P. Varghese, C. Ambrose, S.C. Jin, Y.J. Lim and T. Keisaban. Antioxidant and antiinflammatory activity of eurycomalongifolia jack a traditional medicinal plant in malaysia. IJPSN. 2013; 5(4): 1875-1878.

17. Hai Dang, N.; Choo, Y.Y.; TienDat, N.; Hoai Nam, N.; Van Minh, C.; Lee, J.H. 7-Methoxy(9H- $\beta$-Carbolin-1-il)-(E)-1-Propenoic Acid, a $\beta$ Carboline alkaloid from Eurycoma longifolia, exhibits anti-inflammatory effects by activating the Nrf2/heme oxygenase-1 pathway. J. Cell. Biochem. 2015, 117, 659-670.

18. Tran, T.V.A.; Malainer, C.; Schwaiger, S.; Atanasov, A.G.; Heiss, E.H.; Dirsch, V.M.; Stuppner, H. NF- $\kappa \mathrm{B}$ inhibitors from Eurycoma longifolia. J. Nat. Prod. 2014, 77, 483-488.

19. Yang Y, N Lu, D Chen, L Meng, Y Zheng, R Hui, Effect of n-2 PUFA supplementation on plasma soluble adhesion molecules: a meta analysis of randomized controlled trials. Am. J. ClinNutr 95: 972-80.

20. Myers PR, Minor RL Jr, Guerra R Jr, Bates JN, and Harrison DG. Vasorelaxant properties of the endothelium-derived relaxing factor more closely resemble S-nitrosocysteine than nitric oxide. Nature 345: 161-163, 1990.

21. Shi Q, Vandeberg F. J., Jett C, et. al. Arterial endothelial dysfunction in baboons fed a high cholesterol, high fat diet. Am. J. ClinNutr, 2005; 82: 751-59.

22. Yee Ting Lee, Hiu Yu Lin, Yin Wah Fionna Chan, Ka Hou Christien Li, Olivia Tsz Ling To, Bryan P Yan, Tong Liu, Guangping Li, Wing Tak Wong, Wendy Keung and Gary Tse. Mouse models of atherosclerosis: a historical perspective and recent advances. Lipids Health Dis. 2017; 16: 12.

23. L. Calabresi, M. Gomaraschi, and G. Franceschini. Endothelial protection by highdensity lipoproteins: from bench to bedside. Arteriosclerosis, Thrombosis, and Vascular Biology, 2003; 23 (10): 1724-1731.

24. Uittenbogaard A, Shaul PW, Yuhanna IS, Blair A, Smart EJ. High density lipoprotein prevents 
oxidized low density lipoprotein-induced inhibition of endothelial nitric-oxide synthase localization and activation in caveolae. J Biol Chem. 2000; 275: 11278-11283.

25. Yuhanna IS, Zhu Y, Cox BE, Hahner LD, Osborne-Lawrence $\mathrm{S}$, $\mathrm{Lu} \mathrm{P}$, Marcel YL, Anderson RG, Mendelsohn ME, Hobbs HH, Shaul PW. High-density lipoprotein binding to scavenger receptor-BI activates endothelial nitric oxide synthase. Nat Med. 2001; 7: 853-857.

26. Anderson HD, Rahmutula D, Gardner DG. Tumor necrosis factor-alpha inhibits endothelial nitric-oxide synthase gene promoter activity in bovine aortic endothelial cells. J Biol Chem. 2004; 279: 963-9.

27. Feingold K. R., Marshall M., Gulli R., Moser A. H., Grunfeld C. Effect of endotoxin and cytokines on lipoprotein lipase activity in mice. Arterioscler. Thromb. 1994; 14: 18661872.

28. Furchgott RF. Endothelium-derived relaxing factor: discovery, early studies, and identification as nitric oxide. Biosci Rep. 1999; 19: 235-251.
29. Tran T. V. A.; Malainer C.; Schwaiger S.; Atanasov A. G.; Heiss E. H.; Dirsch V. M.;

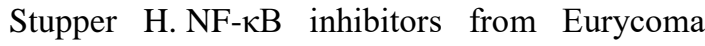
longifolia. J. Nat. Prod. 2014, 77, 483-488.

30. De Martin R.; Hoeth M.; Hofer-Warbinek R.; Schmid J. A. The Transcription Factor NF- $\kappa$ B and the Regulation of Vascular Cell Function. Arterioscler., Thromb., Vasc. Biol. 2000, 20, E83-88.

31. Zhang H.; Sun S. C. NF-кB in inflammation and renal diseases. Cell Biosci. 2015, 5, 63.

32. Yusmazura Zakaria, Azimahtol Hawariah Lope Pihie, Meenakshii Nallappan. Eurycoma longifolia aqueous extract increases sexual activities in male and female rats. The 4th Annual Seminar of National Science Fellowship 2004.

33. Petter Hedlund, Attila Aszodi, Alexander Pfeifer, Per Alm, Franz Hofmann, Marianne Ahmad, Reinhard Fassler, and KarlErik Andersson. Erectile dysfunction in cyclic GMP-dependent kinase I-deficient mice. Proc Natl Acad Sci USA. 2000; 97(5): 2349-2354. 